\title{
Microwave Dielectric behaviour of ketones in solution state at a constant temperature
}

\author{
T.Ganesh ${ }^{1}$, M.Maria Sylvester ${ }^{2}$, S.Bhuvaneswari ${ }^{1}$, P.Jeevanantham ${ }^{3}$, S.Kumar $^{3}$ \\ 1. Post Graduate \& Research Department of Physics Rajah Serfoji Government College, Thanjavur-613 005. \\ Tamil Nadu. \\ 2. Post Graduate \& Research Department of Physics Bishop Heber College, Tiruchirapalli - 620 017. Tamil \\ Nadu. \\ 3. Department of Physics, Annamalai Univeristy, Annamalainagar -608002, Tamil Nadu.
}

\begin{abstract}
The dielectric relaxation time $(\tau)$ and dipole moment $(\mu)$ studies of different molar concentration of acetone and ethylmethyl ketone have been measured at microwave frequency $9.88 \mathrm{GHz}$ and $7.42 \mathrm{GHz}$ in dilute solution of carbon tetrachloride at constant temperature $303 \mathrm{~K}$. The dielectric constant $\left(\varepsilon^{\prime}\right)$ and dielectric loss factor $\left(\varepsilon^{\prime \prime}\right)$ static dielectric constant $\left(\varepsilon_{0}\right)$ and dielectric constant at optical frequency $\left(\varepsilon_{\infty}\right)$ have been determined. The relaxation time $(\tau)$, dipole moment $(\mu)$ and energy of activation $\Delta F(\tau)$ parameter have been determined. The values of relaxation times are not found to be decreases with the increase in the mole fraction of acetone and ethylmethyl ketone mixture. While the dipole moment decreases with the increases in both the systems. Excess volume of binary mixtured solution should be negative for all the systems. The above dielectric parameters which are related with inter, intra molecular association and internal rotation with temperature. The variation of these a parameter that the nature of interaction is depend upon chain length of ketones.
\end{abstract}

Keywords: Dielectric relaxation, Dipole moment, intermolecular interaction, Non-polar solvent effect, relaxation time.

\section{Introduction}

The dielectric relaxation studies of the binary mixture at microwave frequency gives meaningful information about molecular interaction systems. Dielectric investigation of binary polar liquid mixture consisting of one associative and other non-associative liquid provides valuable information regarding molecular complex formation in solution. The strength of the molecular association depends on several factors including the molecular structure, temperature and other factors [1]. The presence of hydrogen bond brings a considerable change in the dielectric properties of liquid mixture, therefore the solution chemistry of these compound can be strongly influenced by the aggregation phenomena. In which it can play a significant role in physical properties like refractive index, dielectric permittivity, density and molar volume. Acetone (ACT) $\left(\mathrm{CH}_{3} \mathrm{COCH}_{3}\right)$ is a dipolar aprotic solvent having high dielectric constant [2], and dipolemoment $\mu=2.84 \mathrm{D}$ in the vapour phase. Ethylmethyl ketone (EMK) is an important organic compound $\left(\mathrm{CH}_{3} \mathrm{C}(\mathrm{O}) \mathrm{CH}_{2} \mathrm{CH}_{3}\right)$ having moderate dielectric constant and dipolemoment $\mu=2.78 \mathrm{D}$ in the vapour phase. Dielectric relaxation studies of polar molecules in non-polar solvent using microwave absorption techniques have been studied by many researchers [3-8].The measurement have been made for the binary mixture of different mole-fraction of acetone and EMK at constant temperate 303K. The dielectric relaxation process has been found using Higasi's method.

During past few years, investigation of dielectric relaxation phenomena provides an important approach to explore the structural behaviour of complex organic polar molecules in non-polar solvent, to study the structural behaviour of molecules. It is necessary to determine various dielectric parameters, which are related with inter and intra molecular association and internal rotation with temperature. When a polar mixture is studied in dilute solutions of a non-polar solvent, its complex dielectric constant is represented by weighted sum of the complex dielectric constant of individual components [9-10]. Obviously, if there is no complex formation of inter association in a mixture, the dependence of dielectric constant, dielectric loss and relaxation time on the concentration of the components should be linear one. The formation of polar complexes leads to relaxation times, considerably larger than those for non-complex molecules[11]. Dielectric relaxation studies are helpful in predicting the presence (or) absence of polar complex in a liquid mixture. It has been observed by schallamach[12] that a binary liquid mixture in which both components are either associated or non associated shows a single relaxation time, where as a binary liquid mixture in which one component is associated and the other is non associated shows two distinct relaxation times.

In the case of Ethylmethylketone (EMK) there is a mesomeric effect due to the hyper-conjugation between the hydrogen atom of methyl substituent and $\pi$ - electrons of phenyl ring .This is called no bond resonance because of this reason the electron density on the carbonyl oxygen of the methyl substituted ketones is also greater than the acetophenone. When the electron density on oxygen atom of ketoxy group is compared 
between chloro and methyl substituted ketones, the chloro substituted stands first. This is because the unshared electron pair on chlorine atom is more free than the bonded electron pair of hydrogen atom. Hence the chloro substituted ketones (or) methyl substituted ketones generally have higher electron density than methyl ketones at the site of molecular interaction.

The nature and extent of the patterns of molecular aggregation that exist in liquid mixtures, resulting from intermolecular interactions [13] have been investigated. The physico-chemical and excess properties of ketone with alcohols and cyclohexane by measurement of ultrasonic speed[14] have also studied. The nature of relative strength of molecular interaction between the components of liquid mixture have been successfully investigated by ultrasonic methods[15-17].The relaxation studies of polar liquids and their binary mixture in dilute solution of non-polar solvent provide valuable information about solute-solute and solvent-solute interaction [18-22]. In our present study the dielectric properties of binary mixture of acetone and Ethyl methylketone with various concentrations at constant temperature $303 \mathrm{~K}$ in dilute solutions of $\mathrm{CCl}_{4}$ have been measured.

\section{Experimental Details}

Acetone and Ethylmethyl ketone, $\mathrm{CCl}_{4}$ Merck GR grade used as without further purification. The static dielectric constant were measured by heterodyne beat method at $303 \mathrm{~K}$ using a commercial instrument Dipolemeter DM01 supplied by wissenchaifftlich Technische Werekstatter, Germany operated at 220V. The refractive indices were measured by Abbe's refractometer with an accuracy of $\pm 0.1^{\circ} \mathrm{C}$, maintained by a water circulating thermostat at constant temp 303K. The viscosities were measured with help of Oswald's viscometer. The time of flow was measured with Rocar stop watch with in accuracy of $0.1 \mathrm{sec}$. The densities were measured by using a $5 \mathrm{ml}$ specific gravity bottle. All the dielectric measurements are measured at microwave frequency $9.84 \mathrm{GHz}$ and $7.4 \mathrm{GHz}$ by using $\mathrm{X}$-band, J-band microwave bench respectively. The binary mixtures of the required mole fraction are prepared by mixing acetone and ethyl methyl ketone with dilute solutions of $\mathrm{CCl}_{4}$ in the calculated proportion. Dielectric measurements are done for the dilute solution of the various mole-fraction of acetone, EMK with $\mathrm{CCl}_{4}$ at constant temp $303 \mathrm{~K}$.

The energy parameters for the binary mixture have been calculated from the knowledge of their dielectric parameters viz. static permittivity $\left(\varepsilon_{0}\right)$, dielectric constant $(\varepsilon)$, dielectric loss factor $\left(\varepsilon^{\prime \prime}\right)$ and optical permittivity $\left(\varepsilon_{\infty}\right)$. From the experimental studies, it is found that the dielectric relaxation process depends on the solute-solute association. The excess parameter is evaluated by using Eyring rate equation at constant temperature 303K. For present investigation double minima method is used for determining the loss factor. The values of $\varepsilon^{\prime}$ and $\varepsilon^{\prime \prime}$ according to this method are given by

$$
\begin{aligned}
& \varepsilon^{\prime}=\left(\frac{\lambda_{0}}{\lambda_{c}}\right)^{2}+\left(\frac{\lambda_{0}}{\lambda_{d}}\right)^{2} \\
& \varepsilon^{\prime \prime}=\frac{2}{\pi}\left(\frac{\lambda_{g}}{\lambda_{d}}\right)^{2}+\left(\frac{\lambda_{0}}{\lambda_{d}}\right)^{2}\left(\frac{d p}{d h}\right)
\end{aligned}
$$

$$
\begin{aligned}
& \text { where } \quad \rho=\frac{\sin \theta}{\frac{1}{2}} \\
& \left(2-\cos ^{2} \theta\right)^{\overline{2}} \\
& \text { and } \\
& \theta=\frac{\pi \Delta x}{\lambda_{g}}
\end{aligned}
$$

Where $\lambda_{\mathrm{c}}$ is the cut-off wave length, $\lambda_{0}$ the free space wave length, $\lambda_{\mathrm{d}}$ the wave length of the dielectric medium, $\lambda_{\mathrm{g}}$ is wave length in the empty wave guide, $\rho$ inverse voltage standing wave ratio, $n$ is the number of minima, $\Delta \mathrm{X}$ is the double minima width in the standing wave patterns. For dilute solutions in non-polar solvents $\varepsilon^{\prime}, \varepsilon^{\prime \prime}$, $\varepsilon_{0}$, and $\varepsilon_{\infty}$ can be expressed as linear functions of concentrations[23-24].

$$
\begin{aligned}
& \varepsilon^{\prime}=\varepsilon^{\prime}+a^{\prime} \mathrm{W}_{2} \\
& \varepsilon^{\prime \prime}=a^{\prime \prime} \mathrm{W}_{2} \\
& \varepsilon_{0}=\varepsilon_{10}+\mathrm{a}_{0} \mathrm{~W}_{2} \\
& \varepsilon_{\infty}=\varepsilon_{1 \infty}+\mathrm{a}_{\infty} \mathrm{W}_{2}
\end{aligned}
$$


Here subscript 1 refers to the pure solvent, 2 to the solute, 0 refers to the static (or) low frequency and $\infty$ refers optical frequency. $W_{2}$ is the weight fraction of the solute. The Higasi's [25] parameters $a^{\prime}, a^{\prime \prime}, a_{0}, a_{\infty}$ are the slopes of the above mentioned equations. From the Higasi's parameters dielectric relaxation time $(\tau)$ is evaluated.

$$
\begin{aligned}
& \tau_{0}=\left(\frac{1}{w}\right)\left[\left(\frac{A^{2}+B^{2}}{C^{2}}\right)\right]^{\frac{1}{2}(1-\alpha)} \\
& A=a^{\prime \prime}\left(a_{0}-a_{\infty}\right) \\
& B=\left(a_{0}-a^{\prime}\right)\left(a^{\prime}-a_{\infty}\right)-\left(a^{\prime \prime}\right)^{2} \\
& C=\left(a^{\prime}-a_{\infty}\right)^{2}+\left(a^{\prime \prime}\right)^{2}
\end{aligned}
$$

The values of the dipole moment $(\mu)$ of the solute molecules for all the binary mixtures are calculated by using Higasi's method.

\section{Results and Discussion}

The dielectric parameters $\varepsilon_{0}, \varepsilon^{\prime}, \varepsilon^{\prime \prime}, \varepsilon_{\infty}$, relaxation time $(\tau)$ and dipole moment $(\mu)$ for binary mixtures in dilute solutions with $\mathrm{CCl}_{4}$ for different mole fractions are determined at constant temperature $303 \mathrm{~K}$ are reported in Table-1, Table-2. Fig-2 shows the increase in static dielectric constant with increase in mole fractions of both binary systems. The basic dielectric parameters $\varepsilon_{0}, \varepsilon^{\prime}, \varepsilon^{\prime \prime}$ vary linearly with the mole fraction of solute in $\mathrm{CCl}_{4}$ for all the binary mixtures. This suggest that there is no change in the nature of the rotating molecular entities in $\mathrm{CCl}_{4}$ solution. Increase in $\varepsilon_{0}, \varepsilon^{\prime}, \varepsilon^{\prime \prime}, \varepsilon_{\infty}$ shows in both system suggest breaking of homo and hetro-association of molecules presented in Table- 3 and Table- 4 respectively. Fig-1 shows the overall dielectric relaxation time $\left(\tau_{0}\right)$ vary non-linearly with the increase in the mole fraction of both binary mixture solutions. The relaxation time depends upon the size and shape of the rotating molecular entities in the solution. The non-linear variation of the relaxation time from its value corresponding to one constituent to the other constituent with the range may be taken as the absence of any solute-solute association in the mixtures. On the other hand non-linear variation of the relaxation time with the mole fraction is interpreted as the solute-solute molecular association in the binary mixtures. The average relaxation time $\left(\tau_{0}\right)$ decreases gradually with the increase of mole fraction of solute in all the binary mixtures, this may possible due to increase in the molar volume. The relaxation time (or) dielectric absorption by its molecule is not solely contributed by their rotation as a single unit, but also contains contribution from the intra molecular rotations of the mixtures. This indicates the existence of an intra molecular relaxation process in addition to the overall relaxation process. It is concluded that in the mixtures, the intramolecular rotations are dominant as compared to the intermolecular rotations. The average relaxation time $\left(\tau_{0}\right)$ decreases with increasing mole fractions may be attributed to decreasing the effective radius of the rotating unit. The relaxation time is a frequency dependent phenomenon, so that relaxation time increases from X-band to J-band. Similarly, $\varepsilon^{\prime}$ and $\varepsilon^{\prime \prime}$ value increases with the frequency decreases. The macro molecular properties viz, density, viscosity, excess viscosity shows the interaction between the molecules will depend upon the structure breaking interaction process.

\section{Acknowledgement}

The authors are gratefully acknowledged the Dr.A.N.Kannappan, Former Professor and Head, Department of Physics Annamalai University, for kindly providing the permission to utilize the laboratory facility.

\section{References}

[1]. Gupta K K, Banshal A K, Singh P J \& Sharma K S , Indian J Pure \& Appl. Phys.,41 (2003) 57.

[2]. Nora E .Hill, Vaughan Worth E, Price A H and Davies Mansel, Dielectric properties and molecular behaviour (Van Nostrand Reinhold company, London), 1969.

[3]. Kumar R, Rangra V.S, Z phys Chem., 219 (2005) 169

[4]. Kumar R, Rangra V.S, Sharma D.R, Thakur N \& Negi N.S , Z Naturforsch , 61a(2006) 197.

[5]. Thenappan T, Prabakar Devaraj A, J Mol Liq., 123(2006) 72.

[6]. Kalaivani T, Kumar S, Krishnan S, Indian J Pure and Appl Phys, 43 (2005) 542.

[7]. Kumar R, Rangra V.S, Sharma D.R , Thakur N \& Negi N.S , Phys Chem Liquids ,45 (2007) 631

[8]. Kumar R, Rangra V.S, Sharma D.R ,Thakur N \& Negi N.S , J Pure \&Appl Phys , 45(2007) 759.

[9]. Madan M.P, Shelfoon M,Cameron I, Can.J.Phys, 55(1977) 878.

[10]. Forest E, Symth C. P, J. Phys.Chem, 69(1965)1302.

[11]. Crossley J, RIC REV [Italy] 4(1971) 69.

[12]. Schallamach A, Trans Faraday Soc. Sec (A) 42 (1946) 180

[13]. Venkatesan P, Chandra Sekaran G, Prabhakara Rao M.V, J Phys. Chem., 44(2006) 281.

[14]. Sumathi T, Priyatharshini S, Punithasri S Indian J Pure and Appl Phys,49(2011) 328. 
[15]. Jalari R ,Sekra Puligundha and Naidu R, J., Chem.Engg.Data 41(1996) 170.

[16]. Miyanga S, Tamurak and Marakami S, J., Chem.Thermodynamics. 24(1992)1077.

[17]. Kiyoharub O, Benson G. C, J.Chem.Thermodynamics 11(1979) 861.

[18]. Yaquba M, Ahmed S.S, Hussainnb A, Pak. J. Sci. Res., 49(2006) 225.

[19]. Kolling O.B, Transactions of the Kansas Academy of science, 82(1979) 218.

[20]. Kumar R, Chaudhary R.K, Rangra V.S, Indian J Pure \& Appl Phys., 49 (2011) 42.

[21]. Madhu Mohan T, Sreehari Sastry S, Murthy V R K, Indian J Pure \& Appl Phys.,48(2010)668

[22]. RituJain, Nidhi Bhargava,Sharma K.S, Bhatnagar D, Indian J Pure \& Appl Phys., 49(2011401

[23]. Franklin, A.D, Hesfton W.H, Henneley E.J \& Smyth C.P, J. Amer. Chem. Soc., 72(1950) 3447

[24]. Higasi K, Bull. Chem. Soc. Japan, 39(1996) 2157.

[25]. Higasi K, Koga Y\&Nagamure M, Bull. Chem. Soc. Japan, 44(1971) 988.

Table -1

Dielectric parameters with different mole fractions of Acetone at 303k

\begin{tabular}{|c|c|c|c|c|c|c|c|c|}
\hline $\begin{array}{c}\text { Conc. } \\
\mathbf{X}_{2} \\
\text { (Mole } \\
\text { fraction) }\end{array}$ & $\underset{\mathrm{Kg} / \mathrm{m}^{3}}{\rho_{12} \times 10^{3}}$ & $\phi_{12}$ & $\varepsilon_{0}$ & $\underset{\left(n_{D}\right)^{2}}{\varepsilon_{\infty}}$ & $\underset{\mathbf{N s m}^{-2}}{\eta_{12} \times 1^{-3}}$ & $\mathbf{P}_{12}$ & $\mu_{\mathrm{ab}}(\mathrm{D})$ & $\underset{\mathbf{N s m}^{-2}}{\eta^{\mathrm{E}} \mathbf{X} \mathbf{1 0}^{-3}}$ \\
\hline 0.02 & 1.5731 & 74.079 & 2.239 & 2.118 & 0.611 & 21.657 & 1.304 & -0.282 \\
\hline 0.04 & 1.5740 & 75.257 & 2.248 & 2.119 & 0.613 & 22.119 & 1.167 & -0.281 \\
\hline 0.06 & 1.5743 & 76.080 & 2.258 & 2.121 & 0.614 & 22.481 & 1.075 & -0.281 \\
\hline 0.08 & 1.5749 & 76.103 & 2.268 & 2.124 & 0.615 & 22.616 & 1.007 & -0.281 \\
\hline 0.10 & 1.5754 & 78.306 & 2.279 & 2.125 & 0.616 & 23.417 & 0.963 & -0.280 \\
\hline
\end{tabular}

Table -2

Dielectric parameters with different mole fractions of Ethyl methyl ketone at 303k

\begin{tabular}{|c|c|c|c|c|c|c|c|c|}
\hline $\begin{array}{c}\text { Conc. } \\
\mathbf{X}_{2} \\
(\text { Mole } \\
\text { fraction })\end{array}$ & $\begin{array}{c}\rho_{12} \times 10^{3} \\
\mathrm{Kg} / \mathrm{m}^{3}\end{array}$ & $\phi_{12}$ & $\varepsilon_{0}$ & $\begin{array}{c}\varepsilon_{\infty} \\
\left(\mathbf{n}_{\mathbf{D}}\right)^{2}\end{array}$ & $\begin{array}{c}\eta_{12} \times 1^{-3} \\
\mathbf{N s m}^{-2}\end{array}$ & $\mathbf{P}_{12}$ & $\mu_{\mathrm{ab}}(\mathrm{D})$ & $\begin{array}{c}\eta^{\mathrm{E}} \underset{3}{X} 10^{-} \\
\mathrm{Nsm}^{-2}\end{array}$ \\
\hline 0.02 & 1.5280 & 75.902 & 2.233 & 2.108 & 0.609 & 22.109 & 1.808 & -0.287 \\
\hline 0.04 & 1.5341 & 76.277 & 2.245 & 2.109 & 0.610 & 22.381 & 1.542 & -0.286 \\
\hline 0.06 & 1.5372 & 77.094 & 2.258 & 2.111 & 0.611 & 22.788 & 1.392 & -0.285 \\
\hline 0.08 & 1.5502 & 77.239 & 2.273 & 2.112 & 0.615 & 23.012 & 1.300 & -0.281 \\
\hline 0.10 & 1.5643 & 77.355 & 2.289 & 2.114 & 0.617 & 23.259 & 1.239 & -0.281 \\
\hline
\end{tabular}

Table -3

Dielectric parameters and activation energies of Acetone in

Carbon tetrachloride System

\begin{tabular}{|c|c|c|c|c|c|c|c|c|}
\hline $\begin{array}{c}\text { Conc. } \\
\begin{array}{c}\mathbf{X}_{\mathbf{2}} \\
(\mathbf{M o l e}\end{array}\end{array}$ & $\begin{array}{c}\boldsymbol{\varepsilon}^{\prime} \\
\mathbf{( X )}\end{array}$ & $\begin{array}{c}\boldsymbol{\varepsilon}^{\prime} \\
(\mathbf{J})\end{array}$ & $\begin{array}{c}\boldsymbol{\varepsilon}^{\prime \prime} \\
(\mathbf{X})\end{array}$ & $\begin{array}{c}\boldsymbol{\varepsilon}^{\prime \prime} \\
(\mathbf{J})\end{array}$ & $\begin{array}{c}\Delta \mathbf{F}_{\tau} \\
(\mathbf{X}) \\
\mathbf{K J} / \mathbf{m o l e}\end{array}$ & $\begin{array}{c}\Delta \mathbf{F}_{\tau} \\
(\mathbf{J}) \\
\mathbf{K J} / \mathbf{m o l e}\end{array}$ & $\begin{array}{c}\boldsymbol{\tau}_{\mathbf{0}} \\
(\mathbf{p s}) \\
(\mathbf{X})\end{array}$ & $\begin{array}{c}\boldsymbol{\tau}_{\mathbf{0}} \\
(\mathbf{p s}) \\
(\mathbf{J})\end{array}$ \\
\hline 0.02 & 2.212 & 2.215 & 0.226 & 0.244 & 7.093 & 7.225 & 2.646 & 2.788 \\
\hline 0.04 & 2.229 & 2.228 & 0.229 & 0.247 & 6.958 & 7.036 & 2.508 & 2.587 \\
\hline 0.06 & 2.239 & 2.241 & 0.231 & 0.249 & 6.277 & 6.556 & 1.914 & 2.147 \\
\hline 0.08 & 2.254 & 2.254 & 0.234 & 0.252 & 6.014 & 6.015 & 1.724 & 1.725 \\
\hline 0.10 & 2.269 & 2.267 & 0.237 & 0.254 & 5.578 & 5.578 & 1.193 & 1.450 \\
\hline
\end{tabular}

Table -4

Dielectric parameters and activation energies of Ethyl methyl ketone in Carbon tetrachloride System

\begin{tabular}{|c|c|c|c|c|c|c|c|c|}
\hline $\begin{array}{c}\text { Conc. } \\
\mathbf{X}_{\mathbf{2}}\end{array}$ & $\begin{array}{c}\boldsymbol{\varepsilon}^{\prime} \\
\left(\begin{array}{l}\text { Mole } \\
\text { fraction) }\end{array}\right.\end{array}$ & $\begin{array}{c}\boldsymbol{\varepsilon}^{\prime} \\
(\mathbf{J})\end{array}$ & $\begin{array}{c}\boldsymbol{\varepsilon}^{\prime \prime} \\
(\mathbf{X})\end{array}$ & $\begin{array}{c}\boldsymbol{\varepsilon}^{\prime \prime} \\
(\mathbf{J})\end{array}$ & $\begin{array}{c}\Delta \mathbf{F}_{\tau} \\
(\mathbf{X}) \\
\mathbf{K J} / \mathbf{m o l e}\end{array}$ & $\begin{array}{c}\Delta \mathbf{F}_{\tau} \\
(\mathbf{J}) \\
\mathbf{K J} / \mathbf{m o l e}\end{array}$ & $\begin{array}{c}\tau_{\mathbf{0}}(\mathbf{p s}) \\
(\mathbf{X})\end{array}$ & $\begin{array}{c}\tau_{\mathbf{0}}(\mathbf{p s}) \\
(\mathbf{J})\end{array}$ \\
\hline 0.02 & 2.225 & 2.225 & 0.252 & 0.247 & 8.758 & 9.395 & 5.124 & 6.597 \\
\hline 0.04 & 2.231 & 2.231 & 0.254 & 0.248 & 7.992 & 8.896 & 3.780 & 5.413 \\
\hline 0.06 & 2.237 & 2.236 & 0.255 & 0.249 & 7.127 & 8.120 & 2.682 & 3.978 \\
\hline 0.08 & 2.242 & 2.241 & 0.256 & 0.250 & 6.085 & 7.230 & 1.773 & 2.794 \\
\hline
\end{tabular}




\begin{tabular}{|l|l|l|l|l|l|l|l|l|}
\hline 0.10 & 2.248 & 2.246 & 0.258 & 0.251 & 4.441 & 6.888 & 0.923 & 2.439 \\
\hline
\end{tabular}

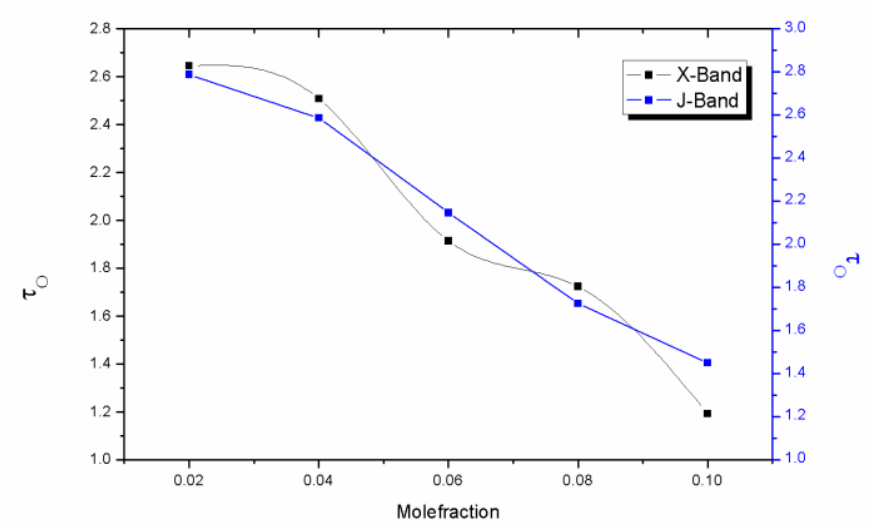

Figure - 1 : Molefraction Vs Relaxation time

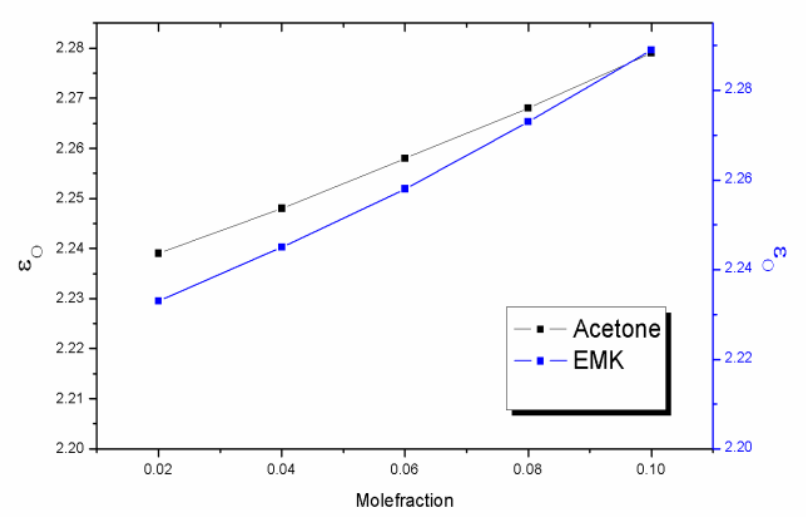

Figure - 2: Molefraction Vs Static dielectric Constant 